\title{
What Discount Rate should Bankruptcy Judges Use? Estimates from Canadian Reorganization Data
}

\author{
Fabrice Barthélémy \\ Université de Cergy-Pontoise (THEMA) \\ Timothy C.G. Fisher \\ University of Sydney \\ Jocelyn Martel \\ Université de Cergy-Pontoise (THEMA) and ESSEC Business School
}

\begin{abstract}
Using data from financial reorganization plans filed by insolvent Canadian firms, we estimate the discount rate implicit in the unsecured creditors' reorganization decision. Using (HARA) utility functions, we find the implicit monthly discount rate of creditors to be $4.9 \%$, which corresponds to an annual discount rate of $77 \%$. This is 7 to 10 times higher than discount rates used in previous empirical studies of reorganization. The discount rate estimates are robust to a range of assumptions about the degree of risk aversion and the market-to-bookvalue ratio of assets.
\end{abstract}




\section{Introduction}

Bankruptcy systems such as the U.S. Bankruptcy Code and the Canadian Bankruptcy and Insolvency Act can be modelled as a multi-stage game. At stage one, the manager of a financially distressed firm decides between liquidation and reorganization. At stage two, if reorganization is chosen, creditors vote on the plan and, if certain conditions are met, the bankruptcy judge confirms it. At stage three, conditional upon the court's confirmation of the plan, the firm must execute the terms of the plan in order to be discharged from bankruptcy.

From the perspective of corporate finance, stage two of the bankruptcy game represents a capital budgeting decision in which creditors choose between two alternatives: rejecting the plan and liquidating the firm's assets, or accepting the plan and the specified structure of repayments of the outstanding debt. Accordingly, creditors will accept the plan if their "participation constraint" is satisfied, i.e., if their expected gain from accepting the plan (reorganization) is larger than their expected gain from rejecting the plan (liquidation). A plan that satisfies the creditors' participation constraint is said, in judicial terms, to pass the "bestinterests test".

Court-supervised reorganization procedures typically require judges to consider the bestinterests test. According to $\S 1129(\mathrm{a})(7)(\mathrm{A})$ of the U.S. Bankruptcy Code, a Chapter 11 plan cannot be confirmed unless creditors receive as much under the plan as under liquidation. Under $\$ 59(2)$ of the Canadian Bankruptcy and Insolvency Act, the bankruptcy court may reject reorganization proposals that are "not calculated to benefit the general body of creditors". Determining whether a plan is in the creditors' interests involves comparing a stream of payments under reorganization to the payment under liquidation. As Klee (1995: 567 - 568) points out, the correct way for the court to do this is to compare the present value of payments under reorganization to the present value of payments under liquidation. Given the present value methodology, a vital issue is then: what discount rate should the court use?

Hitherto, empirical studies evaluating the best-interests test have simply assumed a value for the discount rate. In a study of bankrupt Japanese firms, Eisenberg and Tagashira (1994) assume a 7\% annual discount rate on the basis of the long-term interest rate prevailing over their sample period. Taking into account a higher rate of inflation, Fisher and Martel (1999) assume a 10\% annual interest rate in a study of bankrupt Canadian firms. Given the assumed discount rates, both studies conclude there is substantial compliance with the best interests test in Japan and Canada.

It is clearly desirable to have a sounder basis than assumption for choosing the discount rate a bankruptcy court should use. In this paper, we use data on reorganization and liquidation payments to estimate the discount rate implicit in creditors' reorganization plan decisions. In deciding how to vote on a reorganization plan, we hypothesize that rational creditors compare the expected present value of the payment under reorganization to the expected present value of the payment under liquidation. Everything else equal, the firm will choose the stream of reorganization payments such that the median creditor is indifferent between liquidation and reorganization, i.e., such that the present value of payments in liquidation and reorganization are equal. Thus, given data on the stream of payments in reorganization and liquidation, we can solve for the discount rate of the median creditor.

Our methodology, which involves using a real-world decision posing tradeoffs between payoffs in the near future and a more distant future, has often been used to estimate discount rates for individual consumers. By comparing the tradeoff between price and long-term 
running costs, Hausman (1979) finds that individuals use a discount rate of about $20 \%$ in the purchase decision for air conditioners. Using a similar methodology, Gately (1980) reports implicit discount rates of $45-300 \%$ for the purchase of refrigerators, while Ruderman, Levine, and McMahon (1987) estimate a discount rate of $243 \%$ for gas water heaters. Other studies estimate discount rates implicit in wage-risk tradeoffs in the range $1-14 \%$ [Moore and Viscusi (1990)] and in auto-safety decisions in the range $11-17 \%$ [Dreyfus and Viscusi (1995)]. Warner and Pleeter (2001) estimate discount rates of $0-30 \%$ from the decisions of U.S. military personnel involved in a downsizing program.

For risk neutral creditors, we find that the mean implicit monthly discount rate is equal to $4.9 \%$, which corresponds to an annual discount rate of $77 \%$. This is seven to ten times higher than discount rates typically used in empirical studies of the best-interests test. We examine the impact of risk aversion on the implicit discount rate using (HARA) utility functions. Generally speaking, an increase in risk aversion leads to a reduction in creditors' discount rates into the range of $1.1-4.8 \%$ per month. We also investigate the impact on the estimated discount rates of different assumptions about the market value of assets. We find that a reduction in the market value of assets reduces discount rates, and this result holds for different specifications of the utility function.

The paper is outlined as follows. Section 2 defines the participation constraint for creditors voting on a financial reorganization plan and describes the method used to estimate the implicit discount rate for each observation in the data. Section 3 describes the source data and characteristics of the reorganization plans in the data. Section 4 reports the estimated discount rates under various assumptions about the creditors' degree of risk aversion. Section 4 also investigates how different assumptions about the market value of assets influences the discount rate estimates. Section 5 concludes the article with some of the implications of our results for court-supervised reorganization schemes such as Chapter 11.

\section{The Creditors' Participation Constraint}

Under Canadian insolvency law, ordinary (unsecured) creditors face a choice when a debtor files a reorganization proposal: they can reject the proposal and get the proceeds resulting from the liquidation of the firm's assets, or they can accept the multi-period repayment structure of the proposal. ${ }^{1}$ Under Canadian law, rejection of reorganization necessarily leads to liquidation: there is no other option. The law does, however, allow creditors to propose amendments to proposals before their choice is made.

The value of the payment in liquidation depends on: the market value of liquidated assets, the value of secured claims $(S C)$, the value of preferred claims $(P C)$, administration costs $(A D M I N)$, and the expected time to liquidate the assets $(T)$. We assume the market value of assets is equal to the book value of assets $(A)$, taken from the firm's balance sheet, multiplied by $\delta \leq 1$, to account for the possibility that the market value of assets is less than the book value. In accordance with the priority rule under Canadian bankruptcy law, ordinary creditors receive the proceeds of liquidation after the payment of administration costs, secured claims, and preferred claims. Thus, the value of the payment to ordinary creditors in liquidation is:

\footnotetext{
${ }^{1}$ By and large, Canadian and U.S. bankruptcy laws are very similar, though there are some differences in terminology and procedure. The Canadian counterpart to a Chapter 11 plan is a reorganization proposal. Only ordinary unsecured creditors (as distinct from "preferred" unsecured creditors such as employees) vote on the proposal. Canadian law allows incumbent management to retain control of the firm while mandating the presence of a trustee, who deals with payments to creditors, during reorganization.
} 


$$
\mathrm{L}=\delta A-S C-P C-A D M I N
$$

The value of the payment to ordinary creditors in reorganization is determined by the payment structure specified in the proposal. Let $M_{t}$ be the specified payment at period $t$ and $N$ be the total number of payments in the proposal. ${ }^{2}$ Thus, the reorganization payment structure for a proposal may be represented by a vector $M=\left(M_{1}, \ldots, M_{N}\right)$. The problem for creditors is that $M$ is subject to uncertainty: the firm may default on its payments. Under Canadian law, if a firm defaults on a single payment, reorganization is terminated and the firm is liquidated. We assume that failed reorganization attempts return zero to ordinary creditors. ${ }^{3}$

Given the uncertainty over $M$, one approach is to assume that for each proposed payment $M_{t}$ creditors formulate a probability $p_{t}$ that they will actually be paid. For example, offered a proposal with 3 instalments, in which case $M=\left(M_{1}, M_{2}, M_{3}\right)$, creditors would formulate $p_{1}$ for the probability the payment $M_{1}$ will be received, $p_{2}$ for the probability of receiving $M_{2}$, and $p_{3}$ for the probability of receiving $M_{3}$. We assume creditors have von NeumannMorgenstern preferences, implying the expected utility to a creditor of $M$ is:

$$
U\left(M_{1}, \ldots, M_{N}\right)=\sum_{t=0}^{N} \frac{p_{t} U\left(M_{t}\right)}{(1+r)^{T}}
$$

The intertemporally additive utility function is justified by the structure of the problem. Unsecured creditors are offered a sequence of payments, which are the result of negotiation with the debtor. Once the proposal is accepted by creditors, instalments are independent of one another. Given the intertemporal nature of the contract, each payment must, therefore, be discounted separately at the appropriate rate.

Unfortunately, given the data at hand, estimating a vector of probabilities for each proposal is not feasible. Instead, we assume creditors estimate the probability $p$ that a proposal is successful, i.e., the probability that all the payments in $M$ will be received. Clearly, this is the same as assuming $p=p_{t}$ for all $\mathrm{t}$. In other words, we assume that the hazard rate for proposals (i.e., the probability that a proposal will fail in the next time interval) is constant for the life of the proposal. In keeping with the actual structure of the reorganization procedure, we assume that $p$ is estimated at the time of the vote by creditors.

We assume that ordinary creditors will get paid $L$ at period $T$ with probability equal to one if liquidation is chosen. Thus, the median creditors' 'participation constraint' can be written:

$$
\frac{U(\delta A-S C-P C-A D M I N)}{(1+r)^{T}}=\left[\sum_{t=0}^{N} \frac{U\left(M_{t}\right)}{(1+r)^{T}}\right] p
$$

which states simply that the median ordinary creditor will be indifferent between reorganization and liquidation, and hence just indifferent between participating in reorganization, if the present value of utility in liquidation is equal to the present value of expected utility in reorganization.

\footnotetext{
${ }^{2}$ We assume $M_{t}>0$ for all values of $\mathrm{t}$.

${ }^{3}$ Martel (1995) shows that liquidated firms return a mean of $2.5 \%$ and a median of zero to creditors. Given the higher administrative cost of reorganization, firms that fail reorganization will return even less.
} 
The implicit discount rate on a project, $\mathrm{r}^{*}$, is the rate such that the net present value NPV of the project is equal to zero, that is:

$$
\operatorname{NPV}\left(\mathrm{r}^{*}\right)=\mathrm{PV}_{\mathrm{L}}\left(\mathrm{r}^{*}\right)-\mathrm{PV}_{\mathrm{R}}\left(\mathrm{r}^{*}\right)=0
$$

where $P V_{L}$ is the present value of utility in liquidation (i.e., the left-hand side of (2)) and $P V_{R}$ is the present value of expected utility in reorganization (i.e., the right-hand side of (2)). In view of (2), it is clear that $\mathrm{r}^{*}$ is a function of $\delta, A, S C, P C, A D M I N, M$ and $p$. It is also clear from (3) that the implicit discount rate is simply the internal rate of return in the participation constraint.

To capture creditors' attitudes towards risk, we assume that the utility functions belong to the class of hyperbolic absolute risk aversion (HARA) functions with the following general form:

$$
U(x)=\frac{(1-\gamma)}{\gamma}\left(\frac{a x}{1-\gamma}+b\right)^{\gamma}
$$

where $a>0, \gamma \neq 1, \mathrm{x} \geq 0$. Table 1 shows the utility functions that emerge depending on the values of the parameters. Note that we can retrieve the special case of risk neutrality from the power utility function with $\gamma=1$ and from the negative exponential utility function as $a$ approaches zero. ${ }^{4}$

Each observation (i.e., proposal) in our sample corresponds to a single equation with one unknown variable: the discount rate $r^{*}$. Given the complexity of each equation, an explicit analytical solution cannot be found, so we seek a numerical solution using a grid search method. ${ }^{5}$

\section{Data}

The data in the present study are collected directly from documents filed in court under the Bankruptcy Act by 305 firms in Montreal and Toronto during the period $1977-88$. All of the variables in (2) are observed directly in the data with the exception of $T$, the expected time taken to liquidate the firm's assets, and $p$, the estimated probability of success. We approximate $T$ by the average time in liquidation, which is observed to be 27 months in a similar sample of firms liquidated in Canada [Martel (1995)]. When creditors vote on the proposal they form an estimate of $p$. Following Martel (2004), we model this process by regression. Given the dichotomous nature of reorganization (i.e., success or failure), we use a logit model to estimate the probability of success using the observed outcome for each proposal. ${ }^{6}$

\footnotetext{
${ }^{4}$ The HARA class of utility functions is the most commonly used class of utility function in the finance literature. It gives rise to four special cases: linear (risk neutral), logarithmic, power and negative exponential (all reflecting risk aversion).

${ }^{5}$ Barthélémy, Fisher and Martel (2004) contains a detailed description of the estimation method as well as results from an alternative Newton algorithm.

${ }^{6}$ The logit estimates are available from the authors.
} 
In cases where the (undiscounted) expected utility of reorganization payments received before 27 months is greater than the utility of the liquidation payment at 27 months, it follows that $\mathrm{PV}_{\mathrm{R}}(\mathrm{r})>\mathrm{PV}_{\mathrm{L}}(\mathrm{r})$ for any value of $\mathrm{r}$. Such proposals do not yield any information about the creditors' discount rate. In such cases, bankruptcy judges do not need to worry about using the "correct" discount rate, because it has no effect on the creditors' reorganization decision. We eliminate 110 files from the analysis for this reason. Similarly, firms that offer creditors a zero return in liquidation (i.e., $L=0$ ) do not yield any information about the creditors' discount rate. In such cases, a non-zero return in reorganization, however small, is preferable for creditors and the value of the discount rate irrelevant. We eliminate a further 112 files for which $L=0$. Hence, the final sample for estimation purposes contains 83 observations. Thus, the discount rate is an important consideration in roughly 1 proposal in $4(83$ / 305).

Table 2 provides a snapshot of the characteristics of firms and proposals in the sample. The average value of assets for the firms is $\$ 2.2$ million and the average value of liabilities is $\$ 2.4$ million. It turns out that a majority of firms in the sample have a value of assets less than $\$ 1$ million. Hence, firms reorganizing under the Bankruptcy Act in Canada are small- to medium-size firms. Most claims are ordinary unsecured claims, followed by secured (typically bank), and preferred (typically Crown, i.e., government) claims. ${ }^{7}$ On average, administration costs represent less than $3 \%$ of the book value of assets. Firms in reorganization offer a average payoff rate to (ordinary) unsecured creditors of 43.6 cents on the dollar. In the average proposal this is made up of a cash payment of 2.2 cents with the balance rest paid by instalments over a period of up to 60 months. About half of the reorganization payments are paid within 6 months while the average estimated value of $p$ is $77 \%$.

\section{Results}

To estimate the implicit discount rate for each proposal we start with a base case against which we can compare the impact of creditors' attitude towards risk and other factors. The base case is defined as follows:

1. market value equals the book value of assets $(\delta=1)$;

2. liquidation time of assets is 27 months $(T=27)$;

3. creditors are risk neutral.

Figure 1 illustrates how the grid search process works for a representative observation. The net present value function is plotted against various values of the discount rate. The solution to (2) occurs where the function intersects the horizontal axis, which in this case is at $2.37 \%$. Given that (2) is a higher-order polynomial, we could expect to find multiple solutions for many observations. In fact, only one proposal exhibits multiple solutions (two solutions of $8.4 \%$ and $24.2 \%$ ) and we assume the lower discount rate is the relevant solution. The other 82 solutions to (2) are unique. Results from the grid search are reported in the column headed "Linear" in Table $3 .^{8}$ The mean monthly discount rate is $4.86 \%$, the median is $3.85 \%$; the lowest is $0.079 \%$ and the highest value is $16.10 \%$. We use analysis of variance to determine

\footnotetext{
${ }^{7}$ No firms in the sample have issued bonds. Canada has a special reorganization law (Companies' Creditors' Arrangement Act) for firms issuing bonds. The procedure is used very rarely and there are no extant data on firms that have passed through this procedure.

${ }^{8}$ Individual solutions for all 83 observations in the sample are available from the authors on request.
} 
whether there is any systematic variation in discount rates over the 12 years covered by our data. We find no evidence of statistically significant variation across the sample period and the same result follows whether the data are separated annually, in groups of two years, or in groups of three years. Using the mean value, the annual discount rate for creditors in financial reorganization is equal to $76.7 \%$. This is an order of magnitude greater than discount rates that have previously been assumed in the bankruptcy literature.

\section{Risk aversion}

A risk averse individual is someone who prefers the expected gain of a gamble (safe outcome) over the gamble itself (uncertain outcome). ${ }^{9}$ An alternative definition of risk aversion is that the individual's utility function is concave. Due to concavity of the utility function and the fact that the liquidation payment is larger than the reorganization payment for the 83 files in the sample, introducing risk aversion will have a larger relative impact on the utility of the liquidation payment than on the utility of the reorganization payments. Thus, we would expect to find that the discount rate that solves (2) will be lower in the presence of risk aversion.

The remaining columns of Table 3 report discount rate estimates for the natural logarithmic, negative exponential, and power utility functions. The negative exponential function was estimated for different values of $a$, with risk aversion decreasing as $a$ approaches zero. The power function was also estimated for four different values of $\gamma$, with risk aversion decreasing as $\gamma$ approaches one. Table 3 clearly shows risk aversion lowers the estimated discount rates. The natural $\log$ and all the negative exponential and power utility discount rates are lower than the linear (risk neutral) rates. For the negative exponential utility function estimated discount rates fall as $a$ decreases, reflecting the expected effect of a greater degree of risk aversion on the discount rates. Similarly, the discount rates fall as $\gamma$ decreases for the power utility function.

Table 3 also shows that introducing risk aversion reduces the number of observations. This is due to the sample selection effect described in section 3. In the presence of risk aversion, we eliminate all files for which the expected utility within 27 months is greater than the utility in liquidation, because, given the assumption of 27 months in liquidation, these files satisfy the participation constraint for any positive discount rate. For a given utility function, the number of observations eliminated increases with risk aversion. The drop in observations is largest for the logarithmic function since it exhibits the highest value of absolute risk aversion (for reasonable values of the parameters). ${ }^{10}$

\section{Ratio of market to book value of assets}

Martel (1995) finds evidence consistent with deviations between the book and market value of assets in liquidation $(\delta)$, which could impact the estimated discount rate of ordinary

\footnotetext{
${ }^{9}$ For example, faced with a choice between $\$ 50$ and a gamble with a $50 \%$ chance of paying $\$ 100$ and a $50 \%$ chance of paying nothing (giving an expected value of $\$ 50$ ), a risk averse individual would choose the $\$ 50$ over the gamble.

${ }^{10}$ The measures of ARA $(x)=-U^{\prime \prime} / U^{\prime}$ for the natural logarithmic, negative exponential, and power function are, respectively, $1 /(1+\mathrm{x}), a$, and $-(\gamma-1) / \mathrm{x}$. For the logarithmic, negative exponential, and power utility functions, ARA converges to the linear utility function, respectively, as $\mathrm{x} \rightarrow \infty, a \rightarrow 0$, and $\gamma \rightarrow 1$.
} 
creditors. To see how $\delta$ may impact the discount rate, simplify the participation constraint by assuming that the constant values $S C, P C$ and $A D M I N$ are equal to zero and the success probability of the proposal is equal to one. Thus, the constraint simplifies to:

$$
\frac{U(\delta A)}{(1+r)^{27}}=\sum_{t=0}^{N} \frac{U\left(M_{t}\right)}{(1+r)^{t}}
$$

or, alternatively:

$$
U(\delta A)=\sum_{t=0}^{N} U\left(M_{t}\right)(1+r)^{27-t}
$$

In this setting, there are three types of contract:

Type 1: proposals where all payments to unsecured creditors are made before 27 months;

Type 2: proposals where all payments to unsecured creditors are made after 27 months;

Type 3: proposals with payments made before and after 27 months.

There are 65 Type 1 proposals, 17 Type 3 proposals, and one Type 2 proposal in the sample. The impact on the discount rate of a change in $\delta$ depends on the time structure of the contract, as follows:

$$
\begin{aligned}
& \text { Type 1: }\left.\frac{\partial r}{\partial \delta}\right|_{r^{*}}>0 \\
& \text { Type 2: }\left.\frac{\partial r}{\partial \delta}\right|_{r^{*}}<0 \\
& \text { Type 3: }\left.\frac{\partial r}{\partial \delta}\right|_{r^{*}} \text { is undetermined }
\end{aligned}
$$

These follow from (4). Figure 2 gives an idea of what is going on for a Type 1 observation. As $\delta$ decreases the NPV function shifts to the left. For observations with low discount rates when $\delta=1$, a shift to the left may result in no solution to the problem. Thus, a reduction in $\delta$ has two effects on Type 1 observations: the sample size shrinks as low discount rate observations are dropped from the sample while the remaining observations have lower discount rates.

To keep the analysis tractable, we examine values of $\delta$ between 0.95 and 0.50 in increments of 0.05 . For each observation there exists a value of $\delta$ for which there is no solution to the participation constraint. As $\delta$ decreases, the liquidation value of assets can be reduced to a point where the expected utility in reorganization will always be higher than the utility in liquidation for any reasonable value of the discount rate. This implies that the number of observations for which there exists a solution decreases as $\delta$ falls.

Table 4 shows the estimated discount rates for different values of $\delta$ for the various utility functions. The base case (linear utility) reports a mean monthly discount rate of $4.86 \%$, the 
minimum mean value occurs for $\delta=0.80(4.42 \%)$ and the maximum mean value occurs for $\delta$ $=0.55(6.63 \%)$. As expected, the number of observations for which there exists a solution decreases with $\delta$, going from 83 when $\delta=1$ to 10 when $\delta=0.50$ for linear utility. The important fact that emerges from Table 4 is that, given the utility function, the mean discount rate is quite stable across market-to-book-value ratios.

\section{Conclusion}

Using data on 83 reorganization proposals filed by bankrupt Canadian firms, we compare the payout to creditors from liquidation to the stream of future payments specified in the reorganization proposals. Based on the payment data together with the creditors' participation constraint, we are able to determine the discount rate implicit in the creditors' reorganization decision. Using a base case scenario where investors are assumed to be risk neutral, we estimate the implicit monthly discount rate in reorganization to be equal to $4.86 \%$, which corresponds to an annual discount rate of about $77 \%$. We also find that discount rates decrease as investors become more risk averse.

The assumption implicit in our approach is that creditors are rational economic agents. The assumption implies creditors use all the available information to form an opinion of the probability a proposal will succeed and weight reorganization payments accordingly. Similarly, creditors estimate a return from liquidation. After discounting the two payment streams, creditors decide whether to favour reorganization or liquidation. Do creditors really behave this way? Given widespread use of present value calculations in the business world, the only controversial aspect of our approach would seem to be whether individual creditors have access to enough information to estimate the probability a proposal will succeed. Recall (footnote 1), however, that a trustee is present in all Canadian reorganizations. Since trustees are bankruptcy specialists, it is reasonable to assume that they are able to formulate estimates of the probability a given firm's proposal will succeed (at least informally, based on experience with similar firms perhaps). Provided that trustees are correct, on average, about a firms' probability of success, the model of decision-making presented in the paper will be a close approximation to real-world practice. Put another way, even if creditors had had access to the results in this paper when formulating their reorganization decisions, it is unlikely that many of their decisions would have been different.

In practical terms, our results have two implications for court-supervised reorganization procedures such as Chapter 11 . The first implication is that in many reorganization cases, the creditors' discount rate is irrelevant. This considerably lightens the computational burden on bankruptcy courts evaluating the best-interests test. In cases where the liquidation return is zero, a bankruptcy judge need only check whether creditors are offered a non-zero return in reorganization in order to evaluate the best-interests test. In cases where the liquidation return is positive, a bankruptcy judge need only check whether the sum of reorganization payments before the liquidation payment would be received is greater than the liquidation payment in order to evaluate the best-interests test. In our Canadian data, these two scenarios cover threequarters of the proposals. For the remaining files, however, discount rates are a vital consideration in the best-interests test. Moreover, our results clearly demonstrate that annual rates of the order of $7-10 \%$ are an order of magnitude lower than the rates creditors are likely to be using. Using our estimated discount rates of $77 \%$ rather than those previously considered in the literature will clearly have a major impact of the relative benefits of reorganization and liquidation, potentially yielding drastically different results to the bestinterests test. 


\section{References}

Barthélémy, F., T. Fisher and J. Martel (2004). Estimates of Creditors' Discount Rate in Court-Supervised Reorganization Decisions, Working Paper No. 16, THEMA, Université de Cergy-Pontoise.

Dreyfus, M. and W. Viscusi (1990). Rates of Time Preference and Consumer Valuations of Automobile Safety and Fuel Efficiency. Journal of Law and Economics, 38(1), 79 -105.

Eisenberg, T. and S. Tagashira (1994). Should We Abolish Chapter 11? The Evidence From Japan. Journal of Legal Studies, 23(1), 111 - 157.

Fisher T. and J. Martel, (1999). Should We Abolish Chapter 11 ? Evidence from Canada. Journal of Legal Studies, 28(1), 233 - 257.

Fisher T. and J. Martel (2004). Empirical Estimates of Filtering Failure in Court-Supervised Reorganization. Journal of Empirical Legal Studies, Vol 1(1), 143 -164.

Gately, D. (1980). Individual Discount Rates and the Purchase and Utilization of EnergyUsing Durables: Comment. Bell Journal of Economics, 11(1), 373 - 374.

Green W. (2000). Econometric Analysis (4 ${ }^{\text {th }}$ ed.). New York: Prentice-Hall.

Hausman, J. (1979). Individual Discount Rates and the Purchase and Utilization of EnergyUsing Durables. Bell Journal of Economics, 10(1), 33 - 54.

Klee, K. N. (1995). Adjusting Chapter 11: Fine Tuning the Plan Process. American Bankruptcy Law Journal, 69, 551 - 572.

Martel J. (1995). Commercial Bankruptcy in Canada. Canadian Business Economics, 3(4), $53-64$.

Martel, J. (2004). The Information Content of Financial Reorganization Contracts : Theory and Evidence. Finance, Vol. 24, 143 - 160.

Moore, M. and K. Viscusi (1990). Models for Estimating Discount Rates for Long-Term Health Risks Using Labor Market Data. Journal of Risk and Uncertainty, 3, 381 - 401.

Warner, J. and S. Pleeter (2001). The Personal Discount Rate: Evidence from Military Downsizing Programs. American Economic Review, 91(1) 33 - 53. 
Table 1

HARA Utility Functions

\begin{tabular}{cccl}
\hline$\gamma$ & $\mathrm{b}$ & $\mathrm{U}(\mathrm{x})$ & Special Case \\
\hline 0 & 0 & $\ln (1+\mathrm{x})$ & natural logarithm \\
$-\infty$ & 1 & $-\mathrm{e}^{-\mathrm{ax}}$ & negative exponential \\
$<1$ & 0 & $(1 / \gamma) \mathrm{x}^{\gamma}$ & power \\
1 & 0 & $\mathrm{x}$ & Linear (risk neutral) \\
\hline
\end{tabular}

Note: We use $\ln (1+x)$ to avoid problems when $x=0$ (i.e., monthly payments are equal to zero), for which the logarithmic function would not be defined. 
Table 2

Descriptive Statistics of Firms in Reorganization

\begin{tabular}{lrrrr}
\hline Variable & Mean & Std. Dev. & Min. & Max. \\
\hline Financial Variables & & & & \\
Assets & $2,219.4$ & $4,006.2$ & 48.5 & $25,518.6$ \\
Liabilities & $2,407.6$ & $3,268.0$ & 67.2 & $19,703.0$ \\
Ordinary claims & $1,245.1$ & $1,801.3$ & 24.3 & $8,375.2$ \\
Secured claims & 977.1 & $1,828.2$ & 0.0 & $11,568.2$ \\
Preferred claims & 98.3 & 154.5 & 0.0 & 689.1 \\
Administration costs & 58.4 & 125.5 & 2.0 & $1,008.3$ \\
& & & & \\
Proposal Variables & & & & \\
Total payment & 43.60 & 28.02 & 5.0 & 124.0 \\
Cash payment & 2.23 & 8.85 & 0.0 & 60.2 \\
Payment at 1 month & 8.85 & 16.59 & 0.0 & 100.0 \\
Payment at 3 months & 5.95 & 10.11 & 0.0 & 50.0 \\
Payment at 6 months & 4.28 & 9.54 & 0.0 & 65.0 \\
Payment at 9 months & 3.25 & 7.91 & 0.0 & 50.0 \\
Payment at 12 months & 4.60 & 10.53 & 0.0 & 71.0 \\
Payment at 15 months & 1.72 & 4.33 & 0.0 & 25.0 \\
Payment at 18 months & 2.44 & 6.29 & 0.0 & 40.0 \\
Payment at 21 months & 0.95 & 2.59 & 0.0 & 12.0 \\
Payment at 24 months & 1.89 & 4.85 & 0.0 & 25.0 \\
Payment at 36 months & 5.28 & 17.83 & 0.0 & 123.9 \\
Payment at 48 months & 1.34 & 5.23 & 0.0 & 35.0 \\
Payment at 60 months & 0.82 & 4.75 & 0.0 & 35.0 \\
& & & & \\
Estimated probability of success & 0.770 & 0.152 & 0.426 & 0.998 \\
\hline
\end{tabular}

Notes: $\mathrm{N}=83$ proposals. Dollar values are reported in thousands of December 1998 Canadian dollars, deflated by the GDP deflator (series D20556). The payoff in reorganization and the payments variables are reported in percent. 
Table 3

Summary of Estimated Discount Rates (in \%) for different Utility Functions

\begin{tabular}{|c|c|c|c|c|c|c|c|c|}
\hline & \multirow[t]{2}{*}{ Linear } & \multirow{2}{*}{$\begin{array}{l}\text { Nat } \\
\text { Log }\end{array}$} & \multicolumn{3}{|c|}{ Negative exponential } & \multicolumn{3}{|c|}{ Power } \\
\hline & & & $a=8$ & $a=5$ & $a=1$ & $\gamma=0.8$ & $\gamma=0.5$ & $\gamma=0.1$ \\
\hline Mean & 4.86 & 1.06 & 4.85 & 2.88 & 0.78 & 3.76 & 2.16 & 1.09 \\
\hline Median & 3.85 & 1.16 & 3.85 & 3.18 & 1.08 & 2.91 & 1.89 & 1.16 \\
\hline Std Dev & 4.74 & 0.72 & 4.74 & 1.68 & 0.46 & 3.24 & 1.61 & 0.77 \\
\hline Min & 0.08 & 0.16 & 0.08 & 0.04 & 0.04 & 0.10 & 0.03 & 0.16 \\
\hline Max & 16.10 & 5.58 & 16.01 & 14.74 & 5.41 & 12.48 & 9.10 & 5.59 \\
\hline $\mathrm{N}$ & 83 & 38 & 83 & 62 & 38 & 74 & 56 & 38 \\
\hline \multicolumn{9}{|l|}{ Percentile } \\
\hline 5 & 0.36 & 0.24 & 0.36 & 0.10 & 0.11 & 0.34 & 0.12 & 0.24 \\
\hline 10 & 0.39 & 0.34 & 0.39 & 0.25 & 0.17 & 0.57 & 0.26 & 0.34 \\
\hline 25 & 1.68 & 0.48 & 1.68 & 0.58 & 0.27 & 1.49 & 0.74 & 0.51 \\
\hline 75 & 6.95 & 1.03 & 6.93 & 3.69 & 0.66 & 5.46 & 2.79 & 1.06 \\
\hline 90 & 9.53 & 1.60 & 9.52 & 6.31 & 1.19 & 8.26 & 4.81 & 1.67 \\
\hline 95 & 12.39 & 3.78 & 12.39 & 8.43 & 3.23 & 9.33 & 5.51 & 3.90 \\
\hline
\end{tabular}


Table 4

Impact of $\delta$ on Estimated Discount Rates (in \%) for different Utility Functions

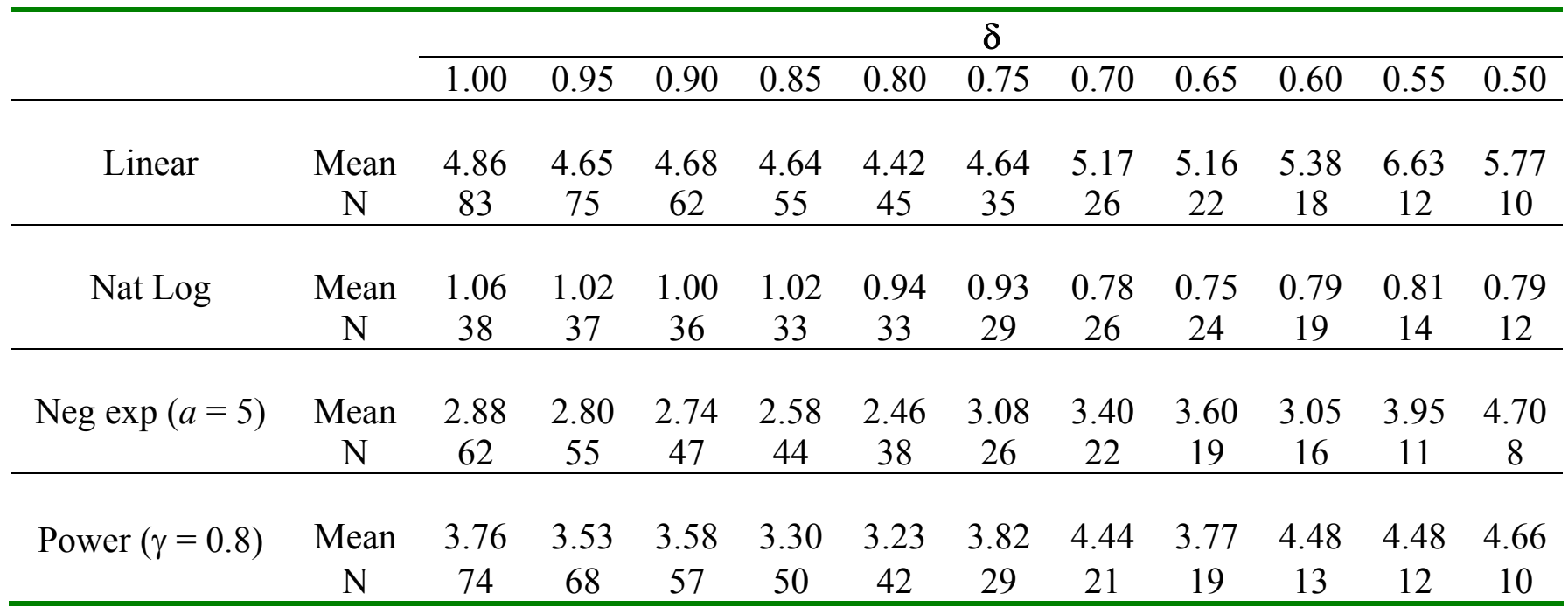


Figure 1: Observation 1 (Risk Neutral Utility Function)

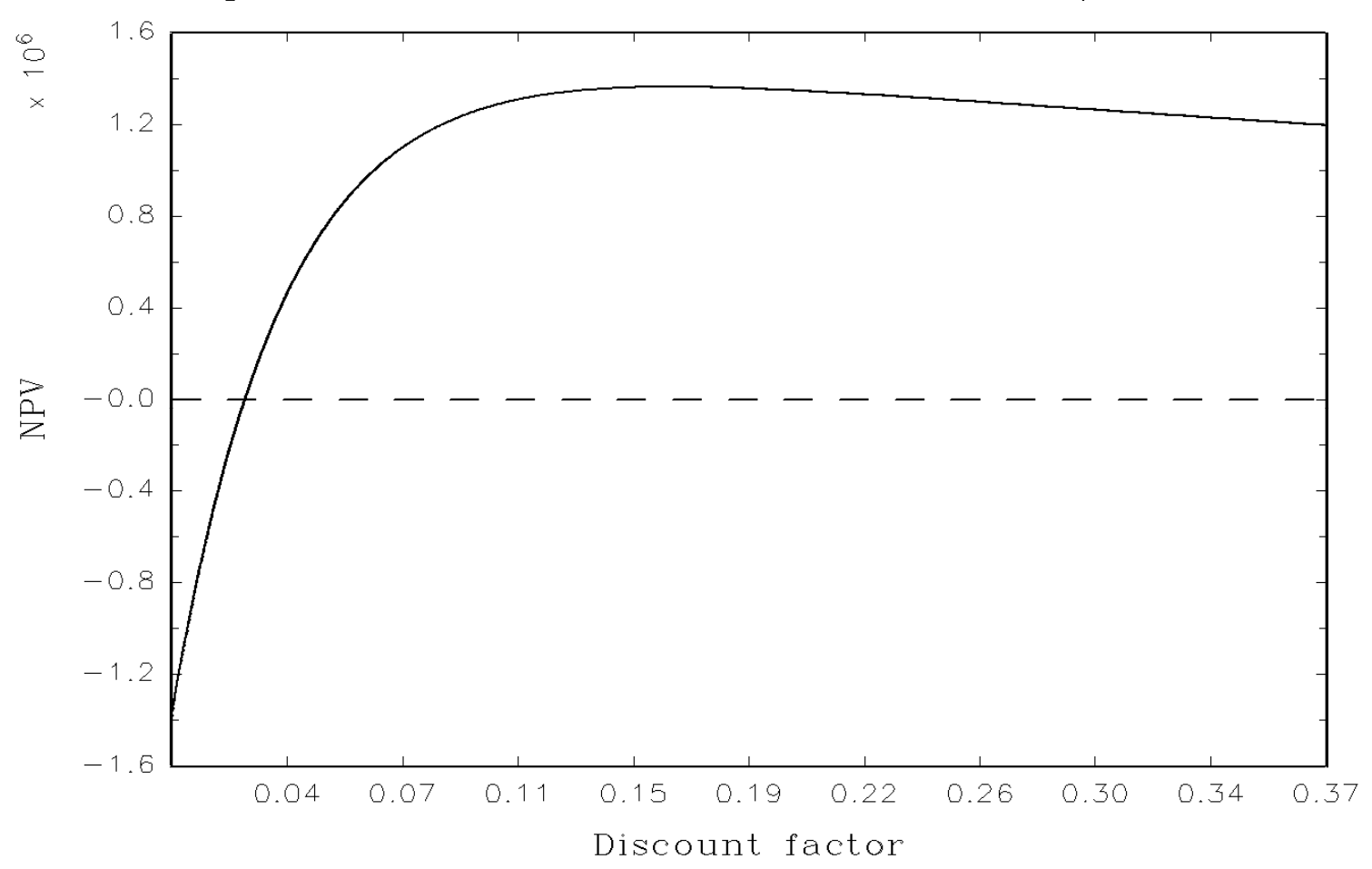


Figure 2: Observation 22 - solution as function of $\delta$ (Risk Neutral Utility Function)

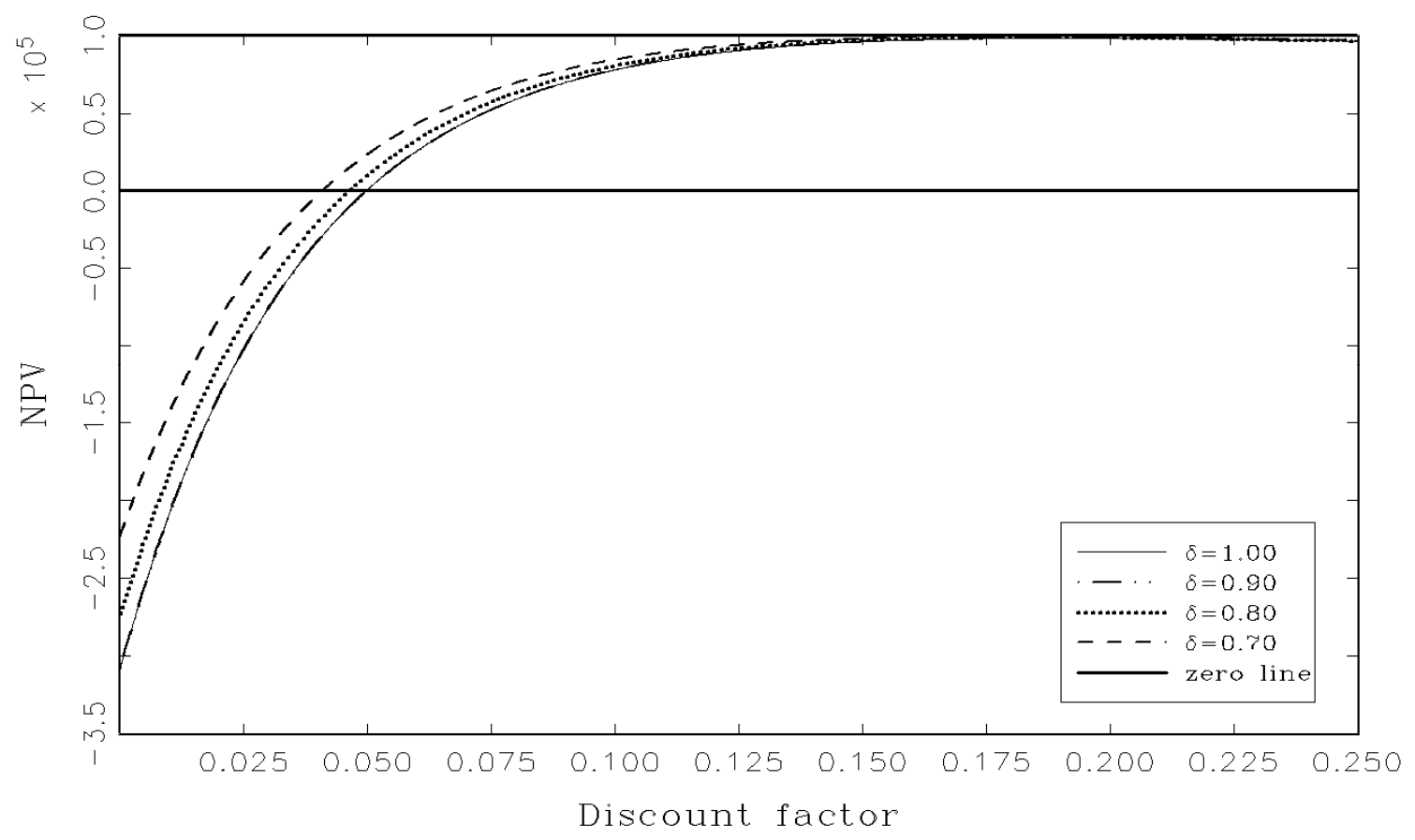

